\title{
Modeling and Simulation of GMA Welding Process and Welding Power Sources
}

\author{
Marjan Golob \\ Faculty of Electrical Engineering and Computer Science, University of Maribor, \\ Smetanova ulica 17, 2000 Maribor, Slovenija; marjan.golob@um.si
}

Simulation Notes Europe SNE 26(4), 2016, 237 - 244

DOI: $10.11128 /$ sne.26.tn10355

Received: November 10, 2016

Accepted: December 5, 2016 (Special Issue Review)

Abstract. Simulation techniques are useful tools for study and research of new welding technologies, and for the rapid development of new control algorithms and control units such as power source circuits, and welding current or voltage controllers. The objective in this research is to combine the simulation of Gas Metal Arc Welding (GMAW) process models with the simulation models of inverter based power machines. The GMAW process is considered as an electrical circuit and the mathematical model is based on physical descriptions of several parts of GMAW process, as are the electric circuit of power supply, the arc dynamics, and the electrode melting process. To establish the validity of the proposed GMAW model, a simple welding application was simulated and welding parameters were derived from experimental conditions. Next, the simulation model of fullbridge DC-DC converter is presented and the discrete PI controller for welding current feedback control is proposed. Both models, the GMAW model and the inverter power supply model, are combined and simulated together. Finaly, the simulation study of firing the thyristors, which enables steady and pulsed direct current welding with a single fully controlled bridge converter is shown.

\section{Introduction}

Conventional approaches to automation of welding have been reasonably successful, but there are still significant opportunities for additional development. Successful implementation of multivariable weld process control involves sensing, modelling, and control.
Process modelling provides a means of incorporating principal and empirical information into a control strategy. Models may be used off-line to evaluate and tune a controller in a simulation. They may also be used to develop transfer functions of a process for use in formal controller design, or to provide maps between input and output parameters. Process models are important bridge between what is known and what is desired.

Several research studies, for example [1]-[4], categorize the GMAW process as an electrical circuit. A mathematical model of the GMAW process is normally developed first. A description of the electric arc is then presented, and all equations are combined into a general model that describes the GMAW process. Simulation methods are used to illustrate the behaviour of the GMAW process. During these simulations the welding power source's dynamic behaviour is often simplified. For most GMAW applications the desired welding conditions are such that time constant of the selfregulating process is shorter than the oscillation rate [2]. With the aim of maintaining a high quality of welding results, the output welding current and voltage must be controlled during the welding process. Furthermore, a real time control system is an important element of modern GMAW welding machine [5], [6].

Modern GMAW equipment is the combination of a sophisticated power electronic device and high performance microprocessor-based control systems. The development process of inverter-based welding power source with the corresponding control system is a complex and expensive process, that requires extensive human and material resources [7]. When using simulation the quality of design process can be improved and the design cost can be significantly reduced. 
Therefore, with the aim of improving the design process, an attempt was made to combine the simulation model of GMAW process with the simulation models of welding power sources [8], [9]. The simulation results are very useful for the rapid development of new control algorithms and the designing of new power sources.

\section{GMAW Process Dynamic Model}

A fundamental significance of GMAW process is that it incorporates automatic feeding of a consumable electrode that is protected by an externally supplied shielding gas as is presented in Figure 1. A constant voltage power supply is fed to the electrode and the workpiece. To get the the desired weld quality, wire feed speed $v_{e}$, torch travel speed $v$, open circuit voltage $u$, and contact tip to workpiece distance $H$ can be adjusted. Here, $h$ is the distance of the center of mass of the droplet above the workpiece. The mathematical model development of a GMAW process is performed by taking into consideration the model of the electrical circuit, the welding wire melting rate, the model of the dynamics of the pendent drop, and the phenomena of the drop transfer mode.

The sum of the voltages around a GMAW circuit, as presented in Figure 1, is

$$
u=R \cdot i+L \frac{d i}{d t}+R_{l} \cdot i+u_{\text {arc }}
$$

where $u$ is open circuit voltage of the power source, $R$ is resistance of the power source, $L$ is inductance of the power source, $i$ is welding current, $R_{l}$ is electrode stickout resistance, and $u_{\text {arc }}$ is arc voltage. Electrode stickout resistance is dependent on resistivity of the electrode stick $\rho$, cross-sectional area of the electrode wire $A$, and electrode stick-out length $l$. It is assumed that $u, R, L, \rho$, and $A$ are constant parameters and $i, l, u_{\text {arc }}$ are dependent variables.

The electrode resistance $R_{l}$ depends on total the length of the electrode stick-out length and drop length $l=l_{s}+l_{d}$. The dynamics of $l_{s}$ depend on the feeding speed of electrode $v_{e}$, the melting speed $v_{m}$, and on the vertical velocity of the contact tip $v_{c}$. The contact tip to workpiece distance (CTWD) is indicated by $H$, and by ignoring the length of the drop $\left(l_{d}=0\right.$ and $\left.l=l_{s}\right)$ the length of the $\operatorname{arc} h$ is:

$$
h=H-l
$$

and, the dynamic of electrode stick-out is given by:

$$
\frac{d i}{d t}=v_{e}-v_{m}+v_{c}
$$

With respect to (2) and (3), the arc length speed is:

$$
\frac{d h}{d t}=v_{m}-v_{e}-v_{c}
$$

the dynamics of the melting speed $v_{m}$ and arc voltage $U_{\text {arc }}$ need to be described in greater detail.

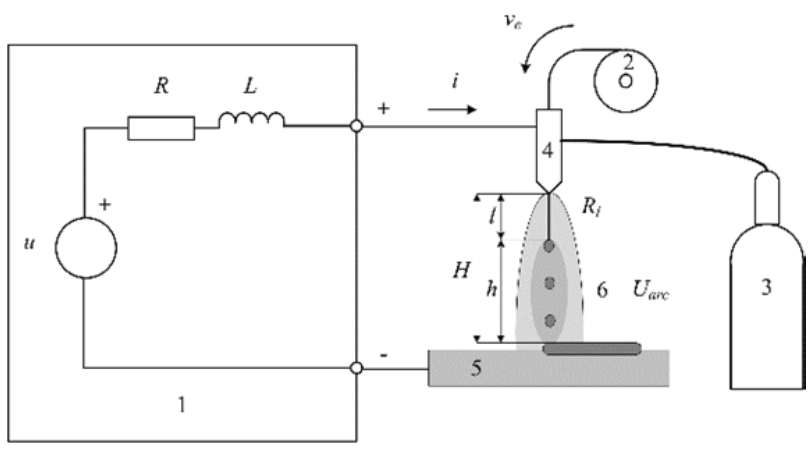

Figure 1: Schematic diagram of GMAW process and electrical circuit of the self-regulating arc process. (1) Power source; (2) wire feed unit; (3) shielding gas; (4) welding gun; (5) workpiece; (6) welding arc and material transfer process.

The total arc voltage $u_{a r c}$, is made up of three separate parts: the anode and cathode drop voltage $u_{a+c}$, the drop voltage in the arc column, which is a function of the electric field strength $E$ and the arc length $h$, and the drop voltage, that depends on current $i$ and arc resistance $R_{a r c}$. In our model we suppose that $u_{a+c}$ is constant. Considering this, the simplest model of the electrical arc is a voltage equation:

$$
u_{\text {arc }}=u_{a+c}+E \cdot h+i \cdot R_{\text {arc }}
$$

When the current flows through the electrode and the arc the electrode is heated by the current flowing through it. This heat depends on the resistance of the welding wire Several studies have described the physical background of a welding wire melting phenomenon. In [9], the research results from a study of anode and cathode melting rates are presented and in [10], the characteristic of melting rate as a function of current, type of gas, and other parameters is reported. In these and other related works [11], [12] the expression for the total melting velocity $v_{m}$ is proposed as:

$$
v_{m}=k_{1} \cdot i+k_{2} \cdot i^{2} \cdot l
$$


where $K_{1}$ and $K_{2}$ are empirical constants for given wire materials and sizes. An equivalent state-space representation is presented below.

$$
\begin{aligned}
\dot{x}_{1} & =\frac{1}{L} \cdot\left(u_{1}-\frac{\rho}{A} \cdot x_{1} \cdot\left(x_{3}-x_{2}\right)\right)-u_{a+c}-E \cdot x_{2} \\
& \quad-\left(R_{a r c}+R\right) \cdot x_{1} \\
\dot{x}_{2} & =k_{1} \cdot x_{1}+k_{2} \cdot x_{1}^{2} \cdot\left(x_{3}-x_{2}\right)-u_{2}-u_{3} \\
\dot{x}_{3} & =u_{3} \\
y & =x_{1}
\end{aligned}
$$

where the states are: $x_{1}=i$ is the welding current, $x_{2}=h$ is the length of the arc, $x_{3}=H$ is the CTWD, and imputs are $u_{1}=u$ is open circuit voltage of the power source, $u_{2}=v_{e}$ is the feeding speed of electrode, and $u_{3}=v_{c}$ is the vertical velocity of the contact tip.

Further parts of GMAW process dynamics, for example the welding drop dynamics, or drop detachment process are also important, but in this model are neglected. On the other hand, in GMAW not only the spray transfer conditions are widely employed, but also the short-circuiting arc's conditions with a relatively small current. This type of material transfer is within the mainstream of high-speed welding regarding thin sheet or overhead position welding of line pipes. Short-circuiting welding is a complicated process in which short-circuiting and arc generations are repeated intermittently. Transfer of molten droplet of mass $m$ involves many complex parameters (more while using $\mathrm{CO} 2$, and other shielding gases). Many researchers have worked on the modeling of the GMAW process. A fifth order nonlinear model of GMAW process has been used by most of the researchers for the control process [1], [3][6].

\section{Welding Power Sources}

A precise control of the arc welding process with its complexity of heat input, material transfer and arc behaviour could be achieved when we use a modern transistor controlled inverter-based power sources. To achieve controlled droplet transfer it is necessary to switch the current level from about $15 \mathrm{~A}$ to $500 \mathrm{~A}$ within less than $200 \mu$ s for a pulse time of $1 \mathrm{~ms}$ and a pulse frequency of $200 \mathrm{~Hz}$. Today the asymmetrical halfbridge-forward-converter became the favourite topology of an inverter power source. IGBTs or MOSFETs are mostly used as power switches dependent on supply voltage and output power range.

\subsection{Inverter based power sources}

The inverter-based welding power supply consists of a rectifier, an inverter switch circuit, a high-frequency ferrite transformer, high-frequency rectifier, and an inductor as is presented in Figure 2.

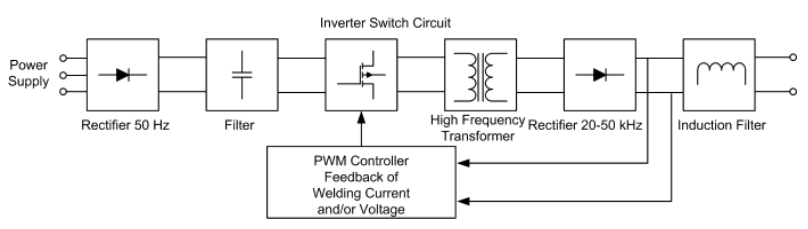

Figure 2: Power supply architecture of modern-inverter based welding machine.

The switch circuits are controlled by microprocessorbased PWM controller units. The schematic of a simulation model of a full-bridge DC-DC converter is shown in Figure 3.

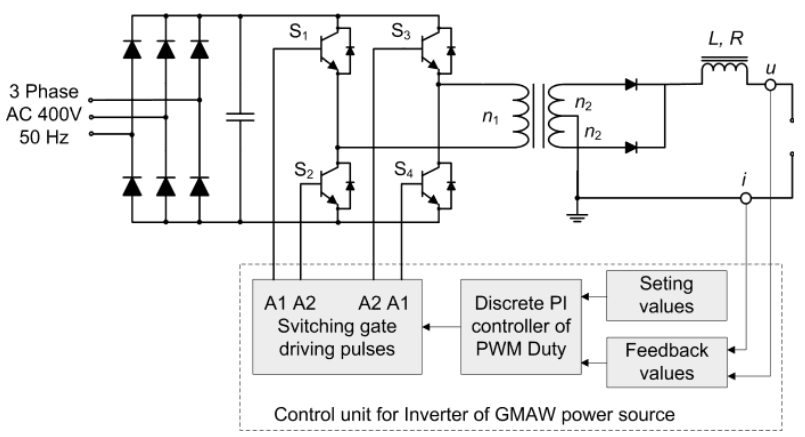

Figure 3: Power supply architecture of modern-inverter based welding machine.

The conventional DC-DC converter operates using a Pulse Width Modulation (PWM) current controller. The DC-DC converter operates at constant switching frequency, which is usually limited to $20-50 \mathrm{kHz}$. The amplitude of the welding current depends on the change of the phase shift between transistors S1, S2, S3, and S4. The PWM signals are generated using a simple circuit and are used for driving four transistors by changing the duty cycle. The duty cycles are usually controlled using feedback controller (voltage, current, or both). In [13] and [14], the implementation studies of proportional integral derivative (PID) are presented.

\subsection{Thyristor based power sources}

The synergic pulsed MIG/MAG welding with widthcontrolled sine-wave current pulses is mostly realised with thyristor-based power sources. 
Such current-pulse waveform could be obtained if a power source is controlled by thyristors integrated, when the pulse frequency is constant and the currentpulse power is controlled by the delay time of the thyristor ignition [15], [16], [17].

The thyristor-based welding power supply consists of a rectifier, an inverter switch circuit, a highfrequency ferrite transformer, high-frequency rectifier, and an inductor as is presented in Figure 4.

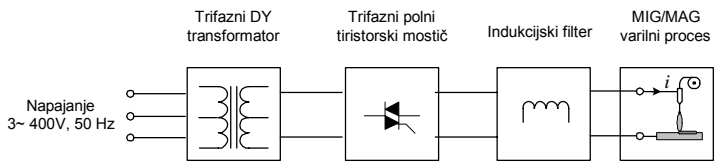

Figure 4: Power supply architecture of modern-inverter based welding machine.

The thyristor-based power sorces produce harmonics in the AC power supply network. In the case of pulsed direct current welding, it is possible, with a proper method of firing the thyristors, to generate both steady direct as well as pulsed direct current with a single fully controlled bridge controller. Using an active filter during pulse welding we could reduce harmonics effectively.

\section{Simulation Examples and Results}

\subsection{Simulation of GMAW Proces}

An automatic welding application was assumed. The parameters derived from experimental conditions are shown in Table 1.

A constant welding speed was assumed. The welding torch was positioned $16 \mathrm{~mm}(H)$ from the work distance. The selected welding wire feed rate $v_{e}=50$ $\mathrm{mm} / \mathrm{s}$ and the open circuit voltage $u=24 \mathrm{~V}$ were set.

The first simulation was performed to find the welding current response when the CTWD was changed from $16 \mathrm{~mm}$ to $12 \mathrm{~mm}$ (at time $2.5 \mathrm{~s}$ ) and back (at time $7.5 \mathrm{~s})$. In addition, the electrode feeding speed $v_{e}$ was changed from $50 \mathrm{~cm} / \mathrm{min}$ to $75 \mathrm{~cm} / \mathrm{min}$ at time $t=5 \mathrm{~s}$.

Figure 5 shows the changes in the welding voltage and current time responses, and the changes of the arc length.

\begin{tabular}{cll}
\hline Parameter & Descr, of the parameter & Value \\
\hline $\mathbf{R}$ & Power source resistance & $0.07 \Omega$ \\
\hline $\mathbf{L}$ & Power source inductance & $0.02 \mathrm{mH}$ \\
\hline $\boldsymbol{\rho}$ & $\begin{array}{l}\text { Specific electrical resistance } \\
\text { of the electrode }\end{array}$ & $0.1 \Omega / \mathrm{m}$ \\
\hline $\mathbf{A}$ & $\begin{array}{l}\text { Cross-sectional area of the } \\
\text { electrode wire }\end{array}$ & $1.02 \cdot 10^{-6} \mathrm{~m}^{2}$ \\
\hline $\mathbf{E}$ & Electric field strength & $675 \mathrm{~V} / \mathrm{m}$ \\
\hline $\mathbf{u}_{\mathbf{a t c}}$ & Arc voltage constant & $11.55 \mathrm{~V}$ \\
\hline $\mathbf{R}_{\mathbf{a r c}}$ & Arc resistance & $0.03 \Omega$ \\
\hline $\mathbf{V}_{\mathbf{e}}$ & Feeding speed of electrode & $0.5 \mathrm{~m} / \mathrm{min}$ \\
\hline $\mathbf{k}_{\mathbf{1}}$ & Empirical constant & $0.626 \mathrm{~m} /(\mathrm{As})$ \\
\hline $\mathbf{k}$ & Empirical constant & $7.55 \cdot 10^{-5}\left(\mathrm{~A}^{2} \mathrm{~s}\right)^{-1}$ \\
\hline $\mathbf{H}$ & $\begin{array}{l}\text { Contact tip to workpiece } \\
\text { distance (CTWD) }\end{array}$ & $0.16 \mathrm{~m}$ \\
\hline
\end{tabular}

Table 1: GMAW process simulation parameters.

The welding current rose and fell with the changes of $H$ and $v_{e}$, as expected. It can be seen from the first plot in Figure 2 that the arc length $h$ (dotted curve) decreased after the $H$ changed from 16 to $12 \mathrm{~mm}$ and then increased back to the previous length. Accordingly, the electrode length $l$ changed from $11.25 \mathrm{~mm}$ to $7.5 \mathrm{~mm}$, which meant that the electrode melted at a higher speed when the current increased. In the second plot of Figure 2 the electrode feeding speed was increased from 50 $\mathrm{mm} / \mathrm{s}$ do $70 \mathrm{~mm} / \mathrm{s}$. This led a reduction of the arc resistance and an increasing of welding current.

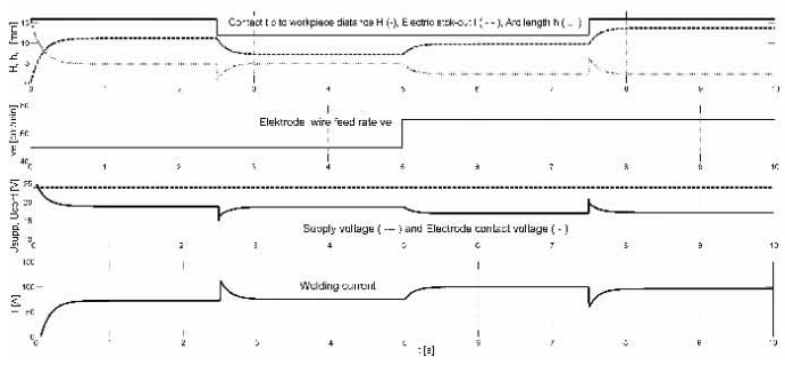

Figure 5: Simulated results of contact to workpiece voltage waveform (third plot) and welding current waveform (fourth plot). Simulation response of the GMAW model when the CTWD was changed from $16 \mathrm{~mm}$ to $12 \mathrm{~mm}$ (first plot) and the electrode feeding speed ve was changed from 0.5 $\mathrm{m} / \mathrm{min}$ to $0.7 \mathrm{~m} / \mathrm{min}$ (second plot). 


\subsection{Simulation of Dynamic Behaviour of a Full-Bridge DC-DC converter}

Simulation of welding source was performed in the program Matlab / Simulink using blocks of the SimPowerSimulation library. A full-bridge circuit is simulated as the topology of the main inverter circuit. The load of the inverter depended on GMAW simulation model and was continuously changing. In Table 2 the design specification of the DC-DC converter and the circuit parameters are described, respectively.

\begin{tabular}{clc}
\hline Parameter & Descr, of the parameter & Value \\
\hline $\mathbf{f}_{\mathbf{s}}$ & Switching frequency & $40 \mathrm{kHz}$ \\
\hline $\mathbf{C}$ & Capacitance & $1 \mu \mathrm{F}$ \\
\hline $\mathbf{P n}$ & Transformer nominal power & $5 \mathrm{~kW}$ \\
\hline $\mathbf{n}_{\mathbf{1}}: \mathbf{n}_{\mathbf{2}}: \mathbf{n}_{\mathbf{2}}$ & Transformer turns ratio & $3.5: 1: 1$ \\
\hline $\mathbf{S}_{\mathbf{1}}-\mathbf{S}_{\mathbf{4}}$ & Ideal switch, IGBT & \\
\hline $\mathbf{R}_{\mathbf{0}}$ & Switch internal resistance & $140 \mathrm{~m} \Omega$ \\
\hline $\mathbf{R}_{\mathbf{S}}$ & Snubber resistance & $1 \mathrm{M} \Omega$ \\
\hline $\mathbf{C}_{\mathbf{s d}}$ & Snubber capacitance & $4.7 \mathrm{nF}$ \\
\hline $\mathbf{T}_{\mathbf{s}}$ & Control sample time & $0.1 \mathrm{~ms}$ \\
\hline $\mathbf{T}_{\mathbf{I}}$ & Pl controller Integral constant & $2 \mathrm{~ms}$ \\
\hline $\mathbf{K}_{\mathbf{p}}$ & Pl controller proportional gain & $0.2 \% / \mathrm{A}$ \\
\hline
\end{tabular}

Table 2: DC-DC converter and other circuit parameters.

The simulation results from the welding using current control feedback and the PWM full-bridge DC-DC converter are shown in Figure 6.

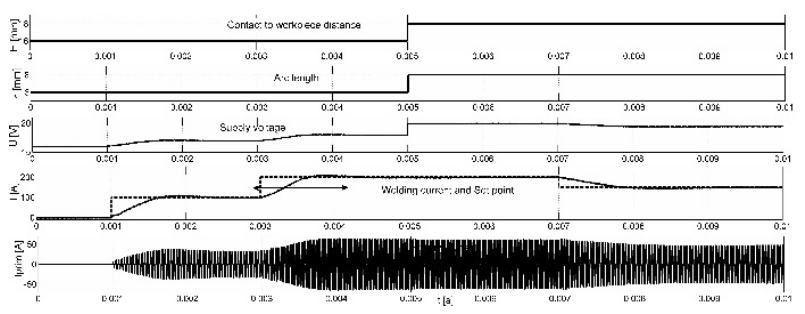

Figure 6: Simulation results of the welding process with current control feedback and PWM full-bridge DC-DC converter-based welding power source. The upper plot shows the change of the CTWD from $16 \mathrm{~mm}$ to $18 \mathrm{~mm}$. The forth plot presents the welding current transient response, and on the fifth plot the time response of the primary current is shown.

Constant welding speed was supposed. The welding torch was positioned at $16 \mathrm{~mm}(H)$ from work distance (CTWD) and after $5 \mathrm{~ms} \mathrm{H}$ was increased to $18 \mathrm{~mm}$, as is presented in the first graph of Figure 5. The welding wire feed-rate $v_{e}$ was set at $70 \mathrm{~mm} / \mathrm{s}$.
After $1 \mathrm{~ms}$ the welding current's set point was increased to $100 \mathrm{~A}$, after $3 \mathrm{~ms}$ to $200 \mathrm{~A}$, and finally after 7 $\mathrm{ms}$ to $150 \mathrm{~A}$. The fourth plot in Figure 5 presents the current control system transient response, which was stable with a small overshoot and was sufficiently fast. On the fifth plot, the time response of the primary current is shown.

For a better presentation of the generated PWM signals the same simulation results were plotted within a time window from about 3 to $4 \mathrm{~ms}$, and marked with an arrow in the fourth graph in Figure 7.

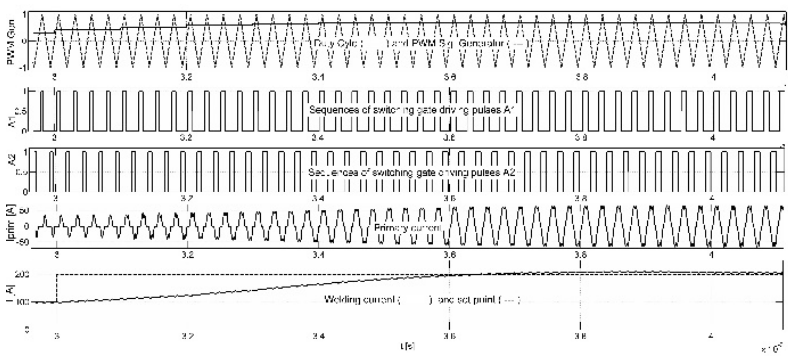

Figure 7: Simulation results of generated PWM signals, which depend on the duty cycle controlled with simple PI controller. The second and third plots show the PWM signals for driving the full-bridge DC-DC converter switches. The fourth and fifth plots show the corresponding changes of primary current and secondary - welding current.

In the first plot of Figure 6, the PWM frequency generator is compared with current controller output (duty cycle). In second and third plots the PWM signals for driving the full-bridge DC-DC converter switches are presented. The periods of pulses A1 and A2 changes depended on the duty cycle determined by the discrete PI controller. The maximum simulation step-size was $0.1 \mu \mathrm{s}$ and the discrete PI controller sample time was $100 \mu \mathrm{s}$.

\subsection{Simulation of Dynamic Behaviour of a Thyristor Based Weldin Power Source}

The power of the welding power source with a threephase transformer in a delta-star connection was set at $50 \mathrm{kVA}$. We selected turns ratio between 4.5 and 6 . In transformer block, we can change all essential parameters, such as resistance and inductance of the primary and secondary windings, and the loss resistance in the core. The thyristor bridge converter was chosen as it reduces the reactive power with firing angle $\alpha$ beyond $60 \operatorname{deg}(\alpha>60 \mathrm{deg})$. 


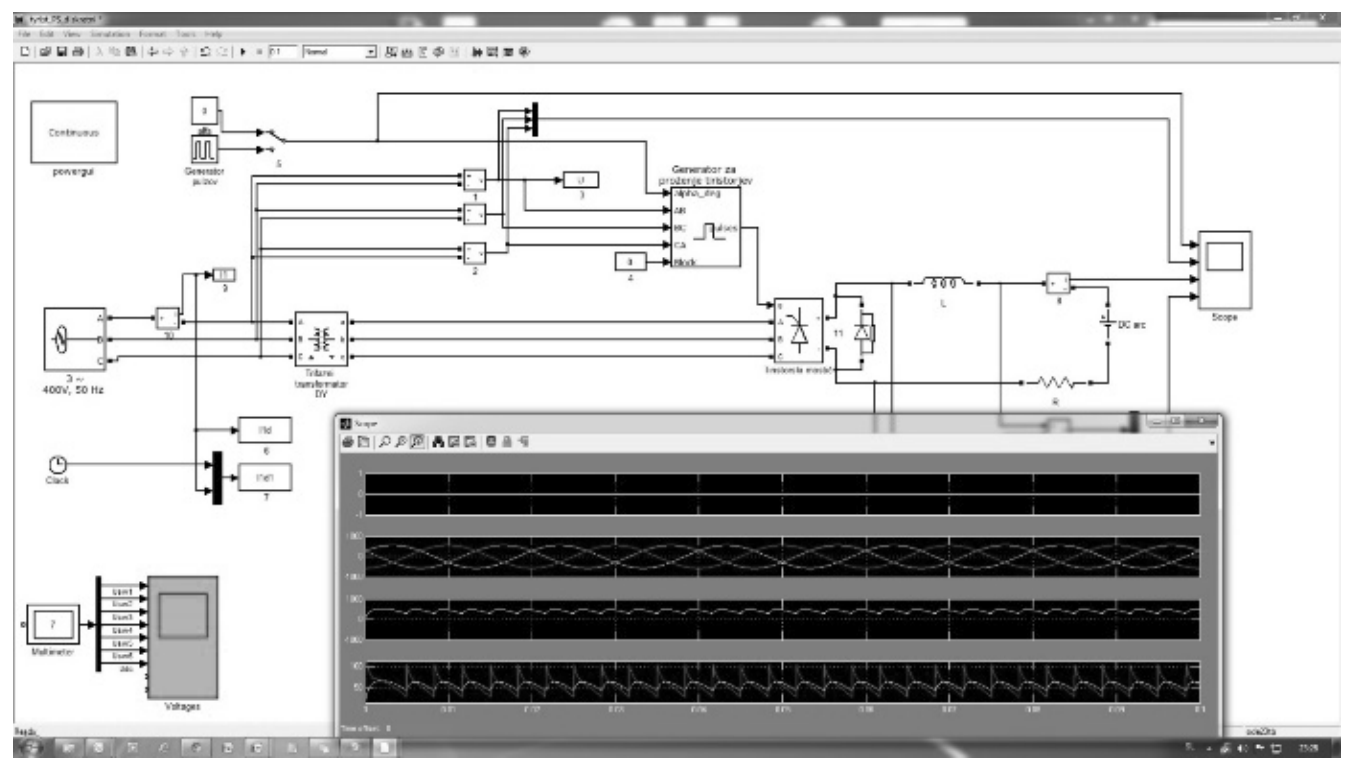

Figure 8: The simulation scheme of a three-phase welding source with thyristor full bridge circuits in Matlab/Simulink. The scope window shows the time graphs of signals within a time window of $100 \mathrm{~ms}$.

For firing angles less than $60 \mathrm{deg}$, the DC voltage of the converter is always positive, and the freewheel diode does not come into operation. As the firing angle advances beyond this point, the load current starts to freewheel through the diode, thus cutting off the input line current and preventing the DC voltage from swinging into the negative direction. This reduces the amount of reactive power drawn from the mains, thus improving its power factor [15]. Figure 8 shows the simulation scheme in the program Matlab/Simulink and simulated voltage and current waveforms in a time window of 100 ms. The simulation was carried out with a firing angle of $0 \mathrm{deg}$.

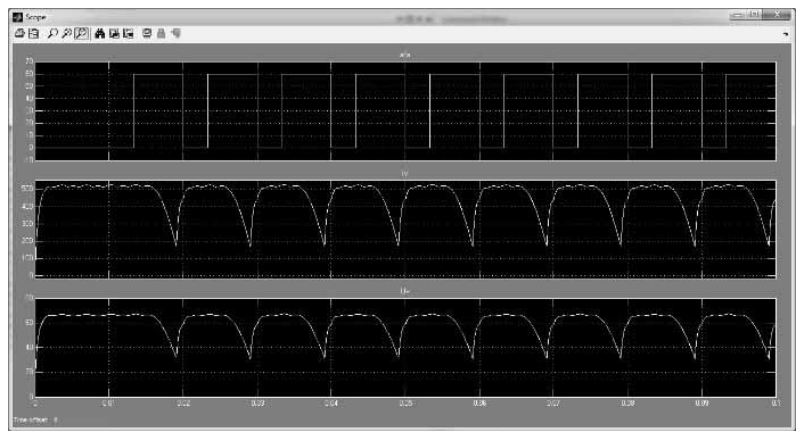

Figure 9: Voltage and current waveforms and variation of the firing angle by pulse frequency $\mathrm{f}_{\mathrm{p}}=100 \mathrm{~Hz}$ and pulse width $t_{p}=6.6 \mathrm{~ms}$.
Figure 9 shows the output voltage, current and firing angle $\alpha$ for the pulse frequency $f_{p}$ of $100 \mathrm{~Hz}$. The firing angle $\alpha$ lies between $\alpha=0$ deg and $\alpha=60 \mathrm{deg}$. The pulse width $t_{P}$ can be varied as well. Figure 10 shows an example of a wider pulse.

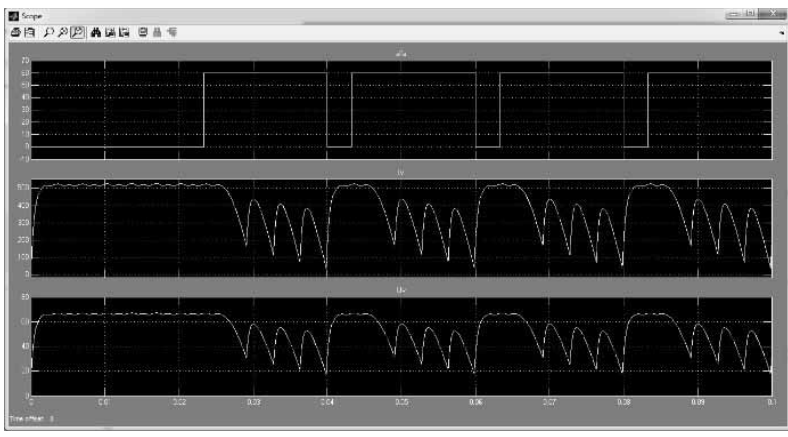

Figure 10: Voltage and current waveforms and variation of the firing angle by pulse frequency $f_{p}=50 \mathrm{~Hz}$ and pulse width $t_{p}=3.3 \mathrm{~ms}$.

Pulsed welding with different pulse frequencies generates different harmonics on the $\mathrm{AC}$ side. The harmonic are accompanied by two adjacent frequencies on the $\mathrm{AC}$ side [15]. The Fourier analysis of the AC current can further verify this. For example, welding with a pulse frequency of $150 \mathrm{~Hz}$ produces harmonics of 100 and $200 \mathrm{~Hz}$ in the alternating current. Figure 11 show the Fourier analysis of the $\mathrm{AC}$ current during the simulation of the pulsed current welding process. 


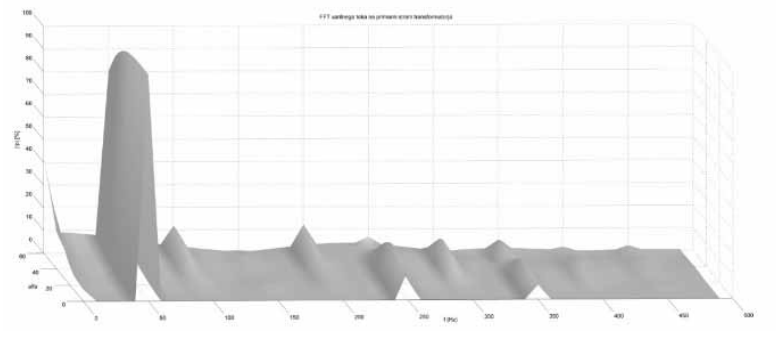

Figure 11: Fourier spectrum of the AC current during pulsed current welding with pulse frequency $\mathrm{fp}$ $=50 \mathrm{~Hz}$ and pulse width $\mathrm{tP}=3.3 \mathrm{~ms}$ by changing the firing angle from 0 deg to $60 \mathrm{deg}$.

\section{Conclusion}

A simulation application has been presented for simulating the GMAW process, inverter-based welding sources, and thyritsor-based welding sources. The mathematical model is based on physical descriptions of several parts of the GMAW process, such as the electric circuits of the power supply, the arc dynamics, the electrode melting process, etc.

The simulation of inverter power source for welding power supply has been proposed and tested together with the GMAW simulation model. The simulation results showed that the conventional full-bridge DC-DC converter with appropriate current feedback controller makes the output welding current follow the set references.

The proposed models and simulations, which are combined together to simulate the power source circuits using simulations of the GMAW process, are suitable for the development of new power source circuits, i.e. resonant converters. By establishing appropriate models of the GMAW process and the full-bridge DC-DC converter model, simulation is an effective tool for investigating new welding technologies, for example the Pulsed GMAW process, or Surface Tension Transfer welding process (STT). Simulation results could be very useful for the rapid development of new control algorithms and for the designing of new inverter control units.

\section{References}

[1] Moore KL, Naidu DS, Yender R, Tyler J. "Arc Welding Control: Part 1 - Modeling and Analysis", Nonlinear Analysis: Theory, Methods \& Applications, vol. 30, pp. 3101-3111, 1997.

[2] Moore KL, Naidu DS, Ozcelik S. Modeling, Sensing and Control of Gas Metal Arc Welding. Oxford, UK: Elsevier Science Ltd., 2003.

[3] Golob M, Koves A, Puklavec A, Torvornik B. "Modelling, simulation and fuzzy control of the GMAW process", in Conf. Proceedings of the 15th International Federation of Automatic Control (IFAC) - Triennial World Congress on Automatic Control, Barcelona, Spain, 2002, vol. 13, pp. 253-258.

[4] Thomsen JS. "Control of Pulsed Gas Metal Arc Welding”, International Journal of Modelling, Identification and Control, vol. 1, no. 2, pp. 115-125, 2006.

[5] Zhang J, Walcott BL. "Adaptive Interval Model Control of Arc Welding Process", IEEE Trans. On Control Systems Technology, vol. 14, pp. 1127 - 1134, Nov. 2006.

[6] Bera MK, Bandyopadhyay B, Paul AK, Robust nonlinear control of GMAW systems-a higher order sliding mode approach. IEEE International Conference on Industrial Technology (ICIT), 2013, 175-180.

[7] Ngo MD, Duy VH, Phuong NT, Kim HK, Kim SB. "Development of digital gas metal arc welding system", Journal of Materials Processing Technology, vol. 198, no. 1-3, pp. 384-391, 2007.

[8] Golob M, Torvornik B, "Modelling, simulation and control of gas metal arc welding", in Proceedings of the 7th Congress on Modelling and Simulation EUROSIM, Prague, Czech Republic, 2010, pp. 347-352.

[9] Golob M. Integrated Models of a Gas Metal ARC Welding Process and Inverter based Power Supply for Process Control Simulation Studies. ELEKTRONIKA IR ELEKTROTECHNIKA. 2014; 20(7): 3-6.

[10] Lesnewich A. "Control of the Melting Rate and Metal Transfer in Gas Shielded Metal Arc Welding - Part 1", Welding Journal, vol. 37, pp. 343s-354s, 1958.

[11] Tusek J, Suban M. "Dependence of Melting Rate in MIG/MAG Welding on the Type of Shielding Gas Used", Journal of Materials Processing Technology, vol. 119, pp. 185-192, 2001.

[12] Halmøy E. "Wire melting rate, droplet temperature and effective anode potential", in Proceedings of the International Conference on Arc Physics and Weld Pool Behaviou, London, England, 1979, pp. 49-57. 
[13] Krejcar O, Spicka I, Frischer R. "Implementation of Full-Featured PID Regulator in Microcontrollers", Electronics and Electrical Engineering, vol. 113, no. 7, pp. 77-82, 2011.

[14] Petrovas A, Lisauskas S, Rinkeviciene R. "Digital Automatic Control System with PID Controller", Electronics and Electrical Engineering, vol. 110, no. 4, pp. 1316, 2011.

[15] Thamodharan M, Beck HP. in Wolf A.: Steady and Pulsed Direct Current Welding with a Single Converter. Supplement to the Weldig Journal, March 1999. 75s-79s.
[16] Langus D, Kralj V. in Grum J: Optimisation of welding parameters in pulsed MIG/MAG welding widthcontrolled sine-wave current pulses. Part 1: Determination of a general synergetic equation and a normalised parametric diagram with a defined parametric welding range. Int. j. mater. prod. technol., 2007, letn. 29, št. $1 / 2 / 3 / 4$, str. $244-254$

[17] Langus D, Kralj V. in Grum J: Optimisation of welding parameters in pulsed MIG/MAG welding widthcontrolled sine-wave current pulses. Part 2: Determination of an optimum material transfer through the arc and a control method. Int. j. mater. prod. technol., 2007, letn. 29, št. 1/2/3/4, str. 255-271. 